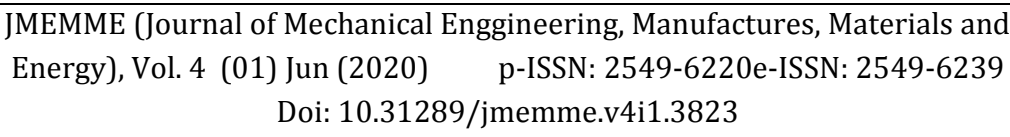

JMEMME (Journal of Mechanical Engineering, Manufactures, Materials and Energy)

\title{
Karakteristik Koefisien Serap Suara Material Concrete Foam Dicampur Serat Tandan Kosong Kelapa Sawit (TKKS) Dengan Metode Impedance Tube
}

\section{Characteristics of the Coefficient of Sound Absorbance Concrete Foam Material Reinforced Oil Palm Empty Fruit Bunch (TKKS) With Impedance Tube Method}

\author{
M. Yusuf R. Siahaan*, Darianto \\ Program Studi Teknik Mesin, Universitas Medan Area \\ Submitted: 01-06-2020 ; Accepted: 20-06-2020 ; Published: 30-06-2020 \\ *Corresponding author: yusufsiahaan@staff.uma.ac.id
}

\begin{abstract}
Abstrak
Perkembangan teknologi di dunia pada saat ini sangat cepat pertumbuhannya, hal ini berbanding lurus terhadap perkembangan peralatan transportasi, industri, informasi, komunikasi maupun hiburan yang menimbulkan kebisingan sehingga mengganggu aktivitas sehari-hari, kenyamanan lingkungan dan kesehatan pada manusia. Suara menjadi bagian dalam kehidupan sehari-hari yang kita kurang sadari fungsi dan eksistensinya. Energi suara datang pada suatu bahan akan dirubah menjadi energi getar (vibrasi) atau energi panas. Bahan yang mampu menyerap suara pada umumnya mempunyai struktur (1) berpori atau (2) berserat. Penelitian ini bertujuan untuk mendapatkan karakteristik serap suara material akustik menggunakan concrete foam dicampur dengan serat tandan kosong kelapa sawit (TKKS). Concrete foam dibuat dengan cara pencampuran bahan semen, pasir, serat TKKS, air, dan foam agent pada alat horizontal shaft mixer kemudian dituangkan pada cetakan. Pembuatan spesimen menggunakan teknik penuangan/pengecoran ke dalam cetakan plat besi dengan proses perendaman selama 7 hari dan proses pengeringan selama 21 hari. Spesimen material concrete foam dan mortar dilakukan pengujian serap suara dengan metode impedance tube. Berdasarkan pengujian impedance tube sesuai dengan ISO 10534-2:1998 bentuk spesimen adalah silinder ukuran $\emptyset 112 \times 10 \mathrm{~mm}$, $\emptyset 112 \times 30 \mathrm{~mm}$, dan $\emptyset 112 \times 50 \mathrm{~mm}$. Pengujian material concrete foam diperkuat serat TKKS sebesar $4 \%$ dengan bentuk silinder ukuran $\emptyset 112 \times 10 \mathrm{~mm}$ diperoleh nilai koefisien serap suara terbaik pada daerah frekuensi menengah $500 \mathrm{~Hz}-2000 \mathrm{~Hz}$ yaitu 0,958 pada frekuensi $1000 \mathrm{~Hz}$, material ini menunjukkan lebih mampu melakukan penyerapan terhadap energi suara yang datang pada permukaan material dibandingkan material mortar memiliki nilai koefisien serap suara terbaik pada daerah frekuensi rendah $0 \mathrm{~Hz}-500 \mathrm{~Hz}$ yaitu 0,818 pada frekuensi $125 \mathrm{~Hz}$ dengan bentuk silinder ukuran $\emptyset 112 \times 30 \mathrm{~mm}$
\end{abstract}

Kata Kunci: Material akustik, concrete foam, serat TKKS , impedance tube, koefisien serap suara.

\begin{abstract}
The development of technology in the world at this time is very fast growing, this is directly proportional to the development of transportation equipment, industry, information, communication and entertainment that cause noise so that it disrupts daily activities, environmental comfort and health in humans. Sound becomes a part of everyday life that we are not aware of its function and existence. Sound energy coming into a material will be converted into vibrational energy (vibration) or heat energy. Materials that are able to absorb sound generally have a structure (1) porous or (2) fibrous. This study aims to obtain the sound absorption characteristics of acoustic material using concrete foam mixed with oil palm empty fruit bunches
\end{abstract}


Siahaan, M.Y.R., Karakteristik Koefisien Serap Suara Material Concrete Foam ....

(TKKS). Concrete foam is made by mixing cement, sand, TKKS fibers, water, and foam agents on a horizontal shaft mixer and then pouring it into a mold. Making specimens using casting / casting techniques into iron plate molds by soaking for 7 days and drying for 21 days. Sound foam and mortar material specimens were tested for sound absorption using the impedance tube method. Based on the impedance tube testing in accordance with ISO 10534-2: 1998 the specimen shape is cylindrical size $\emptyset 112 \times 10 \mathrm{~mm}, \emptyset 112 \times 30 \mathrm{~mm}$, and $\emptyset 112 \times 50 \mathrm{~mm}$. Testing the concrete foam material reinforced by TKKS fiber by $4 \%$ with a cylindrical shape $\emptyset 112 \times 10 \mathrm{~mm}$ obtained the value of the best sound absorption coefficient in the medium frequency area $500 \mathrm{~Hz}-2000 \mathrm{~Hz}$ which is 0.958 at $1000 \mathrm{~Hz}$ frequency, this material shows better ability to absorb sound energy coming on the surface material compared to mortar material has the best sound absorption coefficient in the low frequency $0 \mathrm{~Hz}-500 \mathrm{~Hz}$ region that is 0.818 at $125 \mathrm{~Hz}$ frequency with a cylindrical shape of $\emptyset 112 \times 30 \mathrm{~mm}$.

Keywords: Acoustic materials, concrete foam, TKKS fibers, impedance tube, sound absorption coefficient.

How to Cite: Siahaan, M.Y.R., 2020, Karakteristik Koefisien Serap Suara Material Concrete Foam Dicampur Serat Tandan Kosong Kelapa Sawit (TKKS) Dengan Metode Impedance Tube, JMEMME (Journal of Mechanical Enggineering, Manufactures, Materials and Energy), 4(01): 85-93 


\section{PENDAHULUAN}

Perkembangan teknologi di dunia pada saat ini sangat cepat pertumbuhannya, hal ini berbanding lurus terhadap perkembangan peralatan-peralatan yang digunakan oleh manusia sangat cepat peningkatannya. Peralatan-peralatan yang cepat berkembang diantaranya peralatan transportasi, industri, informasi, komunikasi maupun hiburan. Suara menjadi bagian dalam kehidupan seharihari yang kita kurang sadari fungsi dan eksistensinya. Energi suara datang pada suatu bahan akan dirubah menjadi energi getar (vibrasi) atau energi panas. Beberapa peralatan tersebut tentunya memiliki suara-suara yang menimbulkan kebisingan sehingga mengganggu aktivitas, kenyamanan lingkungan dan kesehatan pada manusia. Maka diperlukan suatu material akustik yang bersifat menyerap suara untuk mencegah perambatan kebisingan sehingga bising yang terjadi dapat direduksi.

Jangkauan frekuensi suara yang dapat didengar oleh telinga manusia antara $20 \mathrm{~Hz}$ sampai $20.000 \mathrm{~Hz}$ [1]. Udara merupakan bahan yang memiliki nilai ketahanan terhadap suara sangat kecil sehingga udara merupakan penyumbang utama terhadap suara kebisingan yang tidak diinginkan di sebuah ruangan. Manusia menginginkan kenyamanan lingkungan yang jauh dari suara bising yang dapat menyebabkan gangguan kesehatan dalam pendengaran, gangguan berkomunikasi, menurunnya performance kerja, kelelahan dan stress.
Jenis bahan peredam suara yang sudah ada yaitu bahan berpori, resonator dan panel [2]. Concrete foam adalah campuran mortar dan foam agent yang menghasilkan struktur material berongga/berpori. Kekuatan beton sangat dipengaruhi oleh sifat dari bahanbahan pembentuk beton yaitu semen, pasir, kerikil, air dan perbandingan campurannya.

Pada umumnya material peredam suara yang banyak digunakan adalah bahan rockwool, glasswool, dan karpet. Untuk membeli panel akustik dibutuhkan biaya yang relatif mahal. Panel akustik type SH0011 dijual seharga 32,46 euro per box (exclude biaya pengiriman barang) [3] tetapi jika dilakukan pembuatan panel akustik dengan material concrete foam dicampur serat TKKS tentunya tidak semahal produk panel akustik type SH0011.

Indonesia merupakan produsen kelapa sawit (crude palm oil/CPO) terbesar di dunia, hal ini ditandai dengan semakin meningkatnya jumlah luas perkebunan-perkebunan baru. Menurut data Ditjen Perkebunan Kementerian Pertanian (Kementan) menyebutkan, luas areal lahan kelapa sawit di Indonesia tahun 2018 mencapai 14.326.350 hektar, sementara di tahun 2020 angka estimasi mencapai 14.996.010 hektar, padahal target Renstra Kementan hanya 14.724.420 hektar. Itu berarti, luas lahan sawit di Indonesia saat ini telah meningkat dibanding tahun 2018 dan melebihi target Renstra Kementan [4].

Tandan Kosong Kelapa Sawit (TKKS) merupakan limbah Pabrik Kelapa Sawit (PKS) yang jumlahnya sangat 
banyak, yaitu 1,9 juta ton berat kering atau setara dengan 4 juta ton berat basah pertahun. PT Perkebunan Nusantara II (PTPN II) menghasilkan limbah TKKS sebanyak 1350 ton pertahun [5]. Pada umumnya material ini dimanfaatkan sebagai pupuk organik dilahan perkebunan dengan cara dibakar atau dibuang kembali kelahan tersebut dan dibiarkan mengalami proses fermentasi secara alami [6].

Limbah TKKS tersebut pada saat ini sudah banyak yang melakukan penelitian untuk dimanfaatkan menjadi produk-produk teknologi. Beberapa penelitian tersebut antara lain: pembuatan bahan komposit berongga (polymeric foam) diperkuat serat TKKS [7], pembuatan papan partikel [8], kerucut lalu lintas [9], parking bumper [10], helmet sepeda [11], dan bahan baku kertas [12]. Pemanfaatan limbah TKKS sampai saat ini masih terbuka luas untuk produk peralatan yang dapat dilakukan terhadap lingkungan sekitar kita menjadi produk yang memiliki nilai ekonomis. Salah satu produk materialnya yaitu material akustil concrete foam.

Untuk mendapatkan karakteristik serap suara material maka dilakukan pengujian yaitu: uji serap suara. Dari beberapa penelitian yang telah dilakukan, belum ada penelitian terhadap material concrete foam yang dicampur serat TKKS dengan respon karakteristik serap suara.

Berdasarkan data dari pabrikan dan atau penelitian yang sudah ada, penulis melihat belum ada suatu penelitian tentang material akustik menggunakan concrete foam dicampur serat TKKS yang diharapkan memiliki nilai koefisien absorpsi paling maksimal atau melebihi nilai koefisien absorpsi yang paling tinggi pada material mortar.

Oleh karena itu, penulis tertarik untuk penelitian terhadap proses pembuatan material concrete foam dicampur serat TKKS menjadi material akustik yang mampu menyerap suara sehingga bising yang terjadi dapat direduksi yang terdiri dari penentuan variasi komposisi antara matrik, serat TKKS dan blowing agent.

Tujuan yang ingin dicapai dalam penelitian ini adalah untuk mendapatkan teknik pembuatan spesimen material akustik dengan bahan concrete foam dicampur serat TKKS dan mendapatkan karakteristik akustik yaitu koefisien serap suara dari material akustik dengan bahan spesimen uji concrete foam dicampur serat TKKS menggunakan metode impedance tube.

Material akustik concrete foam dengan serat TKKS diperkirakan akan mampu menjadi material akustik alternatif yang handal dan murah, untuk itulah pengujian ini dilakukan untuk mengembangkan material akustik baru dan menjadi solusi dari limbah TKKS.

\section{METODE}

\section{Proses Pembuatan Concrete Foam}

Teknik pembuatan concrete foam pada penelitian ini menggunakan metode penuangan/cor ke dalam cetakan setelah diaduk rata dengan menggunakan horizontal shaft mixer dalam wadah pencampuran. Proses pengecoran ini dilakukan untuk menghasilkan beton berongga (foam) dengan mencampurkan pasir, semen, 
serat TKKS dengan air, dan foam agent yang dibangkitkan menggunakan foam generator. Pembuatan concrete foam sebagai material uji impedance tube menggunakan cetakan silinder dengan ukuran $\varnothing 112 \times 300 \quad \mathrm{~mm}$ untuk mendapatkan nilai koefisien serap suara $(\alpha)$ di Research Center for Noise Control and Knowledge-Base in Engineering. Alat cetak impedance tube material concrete foam diperlihatkan pada Gambar 1 .

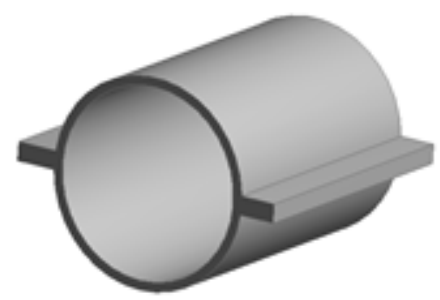

Gambar 1. Cetakan Uji Impedance Tube

Geometri Spesimen Uji Impedance Tube

Geometri untuk spesimen uji impedance tube adalah $\emptyset 112 \times 10 \mathrm{~mm}$, $\emptyset 112 \times 30 \mathrm{~mm}$, dan $\varnothing 112 \times 50 \mathrm{~mm}$ yang sudah disesuaikan dengan ISO 105342:1998 untuk pengujian koefisien serap suara yang terdapat pada Research Center for Noise Control and KnowledgeBase in Engieering. Spesimen uji impedance tube diperlihatkan pada Gambar 2.

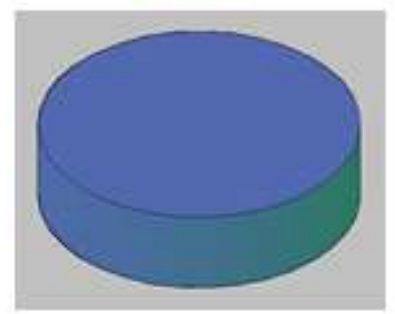

Gambar 2. Spesimen uji Impedance Tube

\section{Alat dan Bahan}

Beberapa alat dalam penelitian ini digunakan untuk metode fisika adalah:

1. Alat uji koefisien serap suara menggunakan Impedance Tube.

2. Horizontal Shaft Mixer.

3. Foam Generator.

4. Mesin Penghalus Serat.

5. Timbangan Digital.

6. Cetakan.

Bahan-bahan yang akan digunakan dalam penelitian ini adalah:

1. Semen

2. Pasir

3. Serat TKKS

4. Air Bersih

5. Surfactane Foaming Agent

Uji Serap Suara.

Material akustik merupakan material penyerap suara yang berfungsi untuk mereduksi kebisingan. Tiap-tiap material akustik memiliki nilai kemampuan penyerapan bunyi yang berbeda-beda.

Jika suatu gelombang bunyi datang pada suatu bidang permukaan batas yang memisahkan dua daerah dengan kecepatan gelombang berbeda maka arah gelombang bunyi yang akan terjadi seperti ditunjukkan pada Gambar 3.

Gambar 3 menjelaskan bahwa: (1) gelombang akan terpantul sempurna

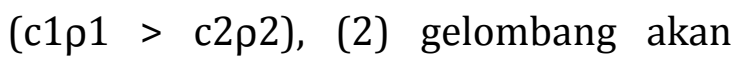
terserap sempurna (c1 $1<\mathrm{c} 2 \rho 2)$, dan (3) gelombang akan sebagian dipantulkan dan sebagian lagi diserap (c1 $1 \approx$ c $2 \rho 2$ ). 
Siahaan, M.Y.R., Karakteristik Koefisien Serap Suara Material Concrete Foam ....

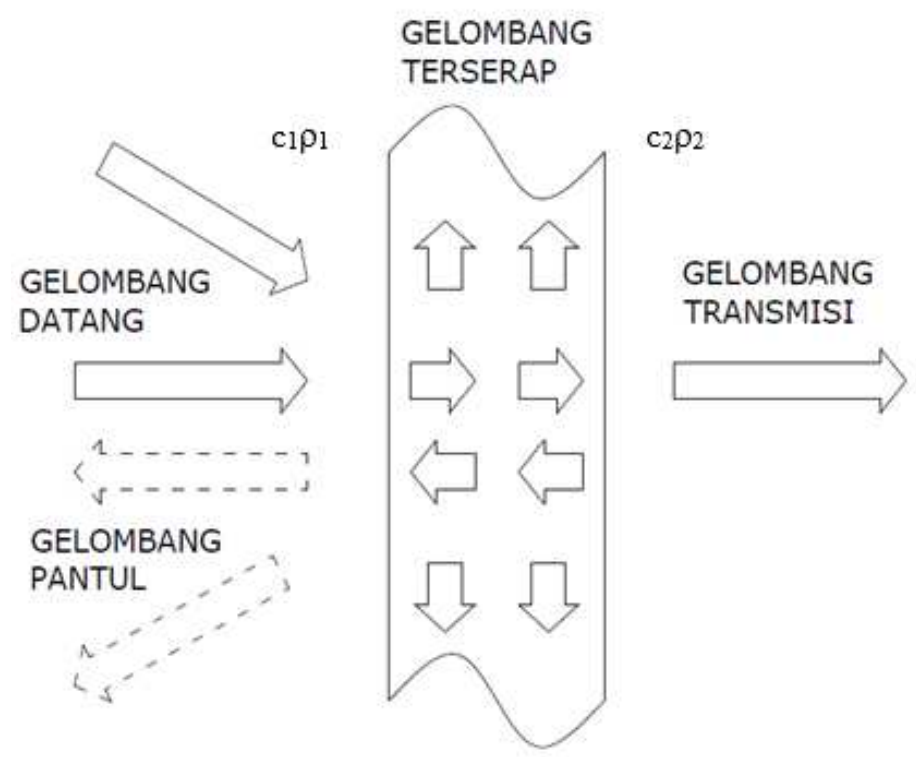

Gambar 3. Arah Gelombang Bunyi [13]

Salah satu metode yang digunakan dalam pengujian serap suara adalah metode pengujian Impedance Tube. Metode pengujian serap suara ini dimaksudkan untuk mendapatkan besarnya koefisien penyerapan bahan terhadap bunyi yang dapat diterima material concrete foam dicampur serat TKKS.

Proses pengujian Impedance Tube dapat dilakukan setelah komponenkomponen pada alat uji saling terhubungkan. Pengujian ini dengan memberikan variasi frekuensi sebesar $125 \mathrm{~Hz}, 250 \mathrm{~Hz}, 500 \mathrm{~Hz}, 1000 \mathrm{~Hz}$, dan
$2000 \mathrm{~Hz}$ terhadap masing-masing material spesimen uji. Hasil dari pemberian variasi frekuensi pada impedance tube adalah harga amplitudo tegangan masing-masing microphone berupa data digital dengan format excel (amplitudo A dan amplitudo B).

Berdasarkan nilai amplitudo tegangan maksimum pada masingmasing microphone maka dilakukan analisa data berdasarkan rumus empiris untuk mengetahui harga koefisien serap bunyi yang dimiliki material spesimen uji tersebut, seperti dilihat pada Gambar 4.

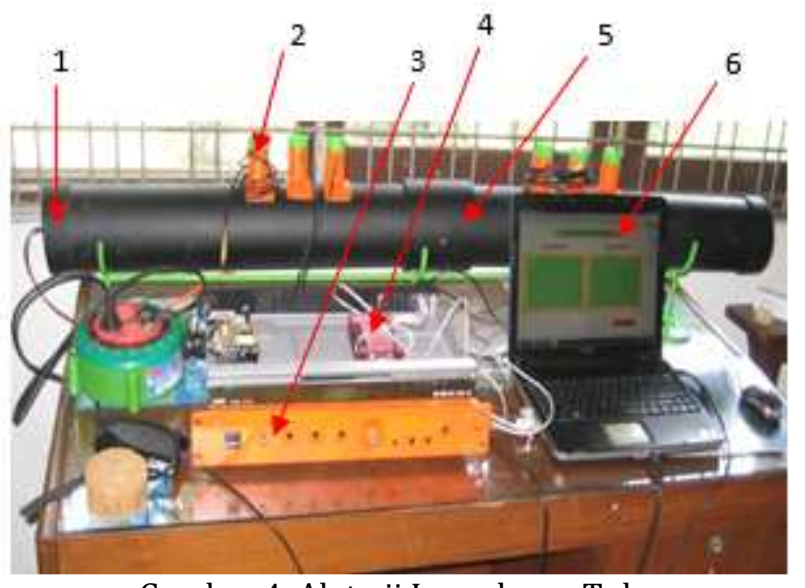

Gambar 4. Alat uji Impedance Tube 
Keterangan gambar:

1. Speaker,

2. Microphone,

3. Preamplifier,

4. Analog digital converter (labjack),

5. Impedance tube,

6. PC/laptop

\section{HASIL \& PEMBAHASAN}

Penelitian ini merupakan pengembangan material baru concrete foam dengan mencari komposisi yang tepat dan karakteristik mekanik yang baik diperoleh berdasarkan beberapa pengujian diantaranya dengan pengujian tekan statik dan pengujian Brazilian [14]. Contoh spesimen uji kubus dan brazilian diperlihatkan pada Gambar 5.

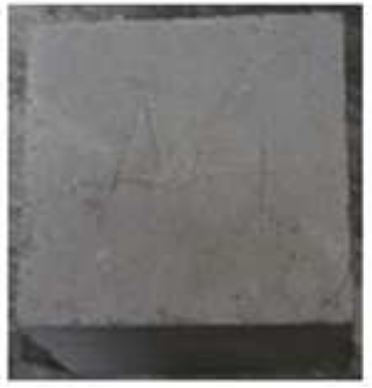

(a)

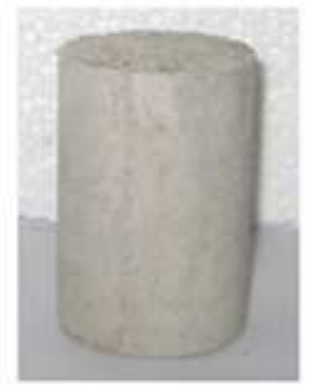

(b)
Gambar 5. Spesimen uji: (a). Tekan statik, dan (b). Brazillian test

Pembuatan spesimen akustik material concrete foam dilakukan dengan metode penuangan/cor bahan mortar (semen, pasir, dan air) dicampur dengan foam agent, dan serat TKKS ke dalam cetakan berukuran silinder $\emptyset 112 \times 300 \mathrm{~mm}$ seperti ditunjukkan pada Gambar 1. Cetakan terbuat dari plat besi dengan tujuan untuk mendapatkan hasil dari pengecoran yang berukuran tetap dan mudah untuk dibuka. Contoh concrete foam untuk spesimen uji impedance tube diperlihatkan pada Gambar 6.

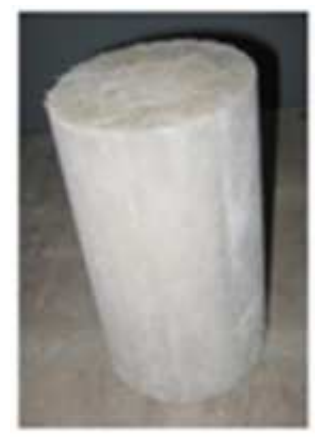

Gambar 6. Spesimen uji Impedance tube

Koefisien serap suara adalah perbandingan antara energi suara yang diserap oleh suatu material terhadap energi suara yang datang pada permukaan material. Koefisien serap suara suatu material diperoleh dengan pengujian impedance tube. Pengujian impedance tube berdasarkan standard ISO 10534-2:1998 dengan spesimen uji bentuk silinder berukuran $\emptyset 112 \times 10 \mathrm{~mm}$, $\emptyset 112 \times 30 \mathrm{~mm}$, dan $\emptyset 112 \times 50 \mathrm{~mm}$. Pengujian spesimen uji dilakukan dengan beberapa variasi frekuensi yaitu $125 \mathrm{~Hz}, 250 \mathrm{~Hz}, 500 \mathrm{~Hz}, 1000 \mathrm{~Hz}$, dan $2000 \mathrm{~Hz}$. Hasil rata-rata koefisien serap suara masing-masing spesimen diperlihatkan pada Gambar 7 s.d 10 . Hasil koefisien serap suara material concrete foam dengan variasi B4 dan material mortar dengan variasi D2 ditunjukkan pada Tabel 1 . Specimen tipe B4 dengan menggunakan variasi ketebalan mempunyai kualitas serap suara pada daerah frekuensi menengah $500 \mathrm{~Hz}-2000 \mathrm{~Hz}$ dan spesimen tipe D2 dengan menggunakan variasi ketebalan mempunyai kualitas serap suara pada daerah frekuensi rendah $0 \mathrm{~Hz}-500 \mathrm{~Hz}$. 
Siahaan, M.Y.R., Karakteristik Koefisien Serap Suara Material Concrete Foam ....

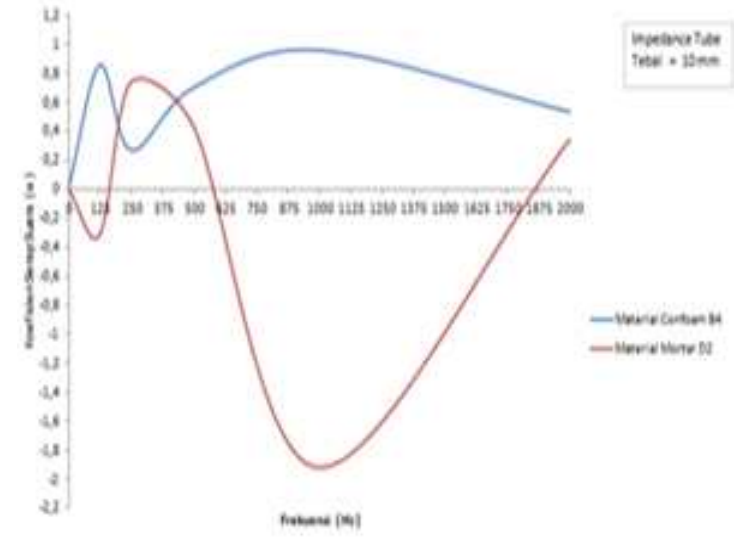

Gambar 7. Grafik koefisien serap suara spesimen Tebal $10 \mathrm{~mm}$

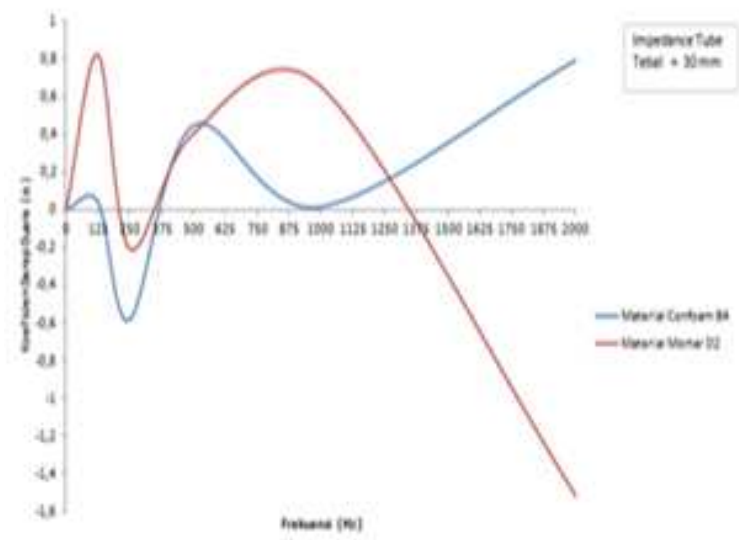

Gambar 8. Grafik koefisien serap suara spesimen Tebal 30mm

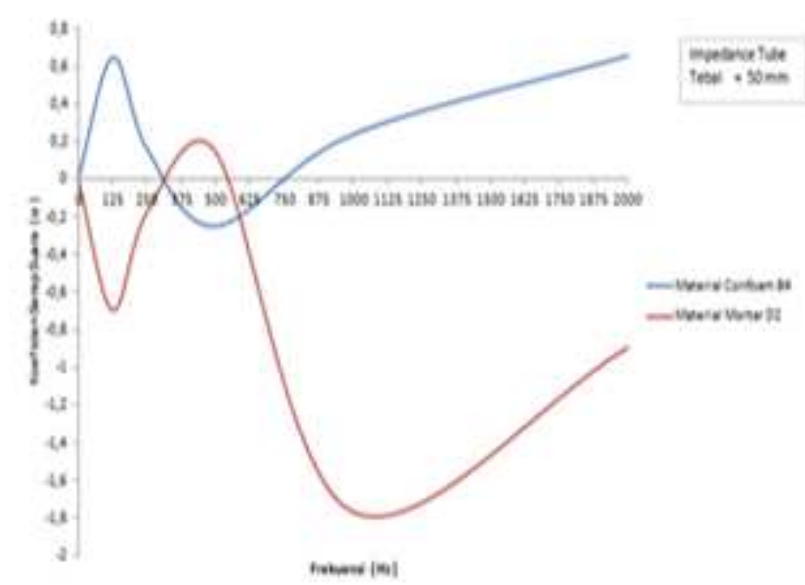

Gambar 9. Grafik koefisien serap suara spesimen Tebal 50mm

Tabel 1. Hasil perhitungan koefisien serap suara pada pengujian impedance tube

\begin{tabular}{ccccccc}
\hline \multirow{2}{*}{ Spesimen } & $\begin{array}{c}\text { Tebal } \\
(\mathrm{mm})\end{array}$ & \multicolumn{5}{c}{ Koefisien Serap Suar (a) } \\
\cline { 3 - 7 } & $125 \mathrm{~Hz}$ & $250 \mathrm{~Hz}$ & $500 \mathrm{~Hz}$ & $1000 \mathrm{~Hz}$ & $2000 \mathrm{~Hz}$ \\
\hline \multirow{3}{*}{ B4 } & 10 & 0,856 & 0,267 & 0,701 & 0,958 & 0,533 \\
& 30 & 0,043 & $-0,584$ & 0,466 & 0,015 & 0,793 \\
& 50 & 0,646 & 0,165 & $-0,249$ & 0,237 & 0,655 \\
\hline \multirow{3}{*}{ D2 } & 10 & $-0,312$ & 0,738 & 0,428 & $-1,915$ & 0,339 \\
& 30 & 0,819 & $-0,207$ & 0,405 & 0,653 & $-1,515$ \\
& 50 & $-0,697$ & $-0,179$ & 0,147 & $-1,771$ & $-0,896$ \\
\hline
\end{tabular}




\section{KESIMPULAN}

Berdasarkan hasil penelitian dan pembahasan yang diperoleh dari beberapa pengujian spesimen material dapat disimpulkan sebagai berikut:

a. Pembuatan concrete foam berhasil dilakukan dengan baik menggunakan metode pengecoran ke dalam cetakan yang terbuat dari plat besi. Alat yang digunakan adalah horizontal shaft mixer sebagai pengaduk mortar, serat TKKS dan foam agent yang telah dibangkitkan menggunakan foam generator.

b. Pengujian dengan impedance tube dilakukan pada spesimen B4 dengan bentuk silinder ukuran $\emptyset 112 \times 10 \mathrm{~mm}$ diperoleh nilai koefisien serap suara terbaik pada daerah frekuensi menengah $500 \mathrm{~Hz}-2000 \mathrm{~Hz}$ yaitu 0,958 pada frekuensi $1000 \mathrm{~Hz}$. Spesimen B4 merupakan material concrete foam diperkuat serat TKKS sebesar 4\% menunjukkan lebih mampu melakukan penyerapan terhadap energi suara yang datang pada permukaan material dibandingkan dengan spesimen D2 merupakan material mortar memiliki nilai koefisien serap suara terbaik pada daerah frekuensi rendah $0 \mathrm{~Hz}-500 \mathrm{~Hz}$ yaitu 0,818 pada frekuensi $125 \mathrm{~Hz}$ dengan bentuk silinder ukuran $\emptyset 112 \times 30 \mathrm{~mm}$.

\section{REFERENSI}

[1]. Rusli Kustaman, Sound and Human, ProTVF, Volume 1, Nomor 2, Hal. 117124, September 2017.

[2]. Lee, Y and Changwhen Joo, Sound Absorption Properties of Recycled Polyster Fibrous Assembly Absorbers,
AUTEX Research Jurnal, vol. 3 No. 2, Juni 2003.

[3]. Muftil Badri M, Respon Polymeric Foam Yang Diperkuat Serat Tandan Kosong Kelapa Sawit (TKKS) Akibat Beban Tekan Statik dan Impak (Simulasi Numerik), Universitas Sumatera Utara, 2011.

[4]. Subianto, Bambang, dkk., Utilization of Fruit Bunch Waste from Oil and Palm Industry for Paerticleboard Using Phenol Formaldehyde Adhesive, Wasta PPKS: 1-4

[5]. A. J. Zulfikar, B. Umroh and M. Y. Siahaan, "Investigation of Mechanical Behavior of Polymeric Foam Materials Reinforced by Oil Palm Empty Fruit Bunches (OPEFB) Fibers Due to Static and Dynamic Loads," JMEMME, vol. 3, no. 1, pp. 10-19, 2019.

[6]. Syam B, Weriono and Rahmawati, Analysis of Concrete and Rubber Base of Traffic Cone Subjected to Impact Loading, (accepted to be presented in the 6th Int. Conf on Numerical Analysis in Engineering), Lombok Island, Indonesia, May 2009.

[7]. Yani Muhammad, Desain dsn Pembuatan Helmet Sepeda Bahan Komposit Polymeric Foam Diperkuat Serat TKKS, Universitas Sumatera Utara, 2011.

[8]. Nuryanto,E. Pemanfaatan Tandan Kosong Kelapa Sawit Sebagai Sumber Bahan Kimia, Warta PPKS: 137-144.2004.

[9]. Zulfian, Fisika Bangunan Akustik, UNSYIAH, Banda Aceh, 2004

[1o N.Fitriadi, Penyelidikan Perilaku Mekanik Material Concrete Foam Diperkuat Serat TKKS Terhadap Beban Statik dan Impak, Universitas Sumatera Utara, 2015. 